\title{
A Pre-capstone Junior-level Structural and Materials Design Project for Civil Engineering Students: Glue Laminated Timber Design
}

\section{Dr. Nicholas Andres Brake, Lamar University}

Nicholas Brake is currently an Assistant Professor in the civil and environmental department at Lamar University. He received his B.S. (2005), M.S. (2008), and Ph.D. (2012) from Michigan State University. His area of expertise is in cementitious composites which includes: fracture and fatigue mechanics of quasi-brittle materials, recycled concrete, conductive concrete, reinforced concrete, pervious concrete, geopolymer, and structural dynamics. He currently teaches a wide array of courses that includes statics, reinforced concrete design, structural analysis, and materials engineering. Dr. Brake actively integrates project based and peer assisted learning pedagogies into his curriculum. 


\title{
A pre-capstone junior-level structural and materials design project for civil engineering students: glue laminated timber design
}

\begin{abstract}
Senior level civil engineering students in our department often struggle in the early stages of their capstone senior design project because of their unfamiliarity with building codes and design philosophies, and often lack an ability to solve open-ended design problems. Introducing students to design philosophies, building codes, and some simplified design projects in their junior year can help in their preparation for their capstone project by enhancing their confidence, preparedness, and capacity to solve open-ended engineering design problems. In this evidencebased paper, the impact of a junior-level pre-capstone design project involving the design and optimization a glue laminated timber beam is discussed. The project required junior-level students to calculate the wind, live, and dead loads per ASCE 7-10, use software (STAADPro) to calculate the determine the structural demand, conduct knot timber surveys, determine strength modification factors per ASTM D3737, design the structural members per 2015 AWC national design specifications for wood construction, construct and test a small-scale glulam beam, and develop an oral presentation to summarize the results. After completion of the project, students were found to have relatively high engineering self-efficacy, motivation, and expectancy. The students who completed the pre-capstone project also indicated more curricular emphasis was placed on engineering design and the building codes compared to recent graduates who were not given the project. The students were also found to have higher levels of confidence in engineering design and ability to use tools to solve modern engineering problems.
\end{abstract}

\section{Introduction}

Over the last few decades, growing industrial and technical demands have required that engineering departments shift towards more of a technical and scientific knowledge acquisition centric curricula $^{1}$ that places less emphasis on broad, practical, and creative enterprises ${ }^{2,3}$. Students graduating from non-design centric curricula have several weaknesses according to the literature, which include: little exposure to ill-defined problems, teamwork was largely ineffective or uncommon, insufficient attention was given to communication, and students had issues conceptualizing and formulating problems, among others ${ }^{4}$. Engineering design is an iterative process that encompasses multiple creative, analytical, building, and testing components to finally arrive at one or more working solutions. According to the Massachusetts Department of Education ${ }^{5}$, the engineering design process encompasses eight major iterative components: identifying a need or problem, research the need or problem, develop possible solutions, select the best possible solutions, construct a prototype, test and evaluate, communicate the solution, and redesign. The design loop is shown graphically in Figure 1. 


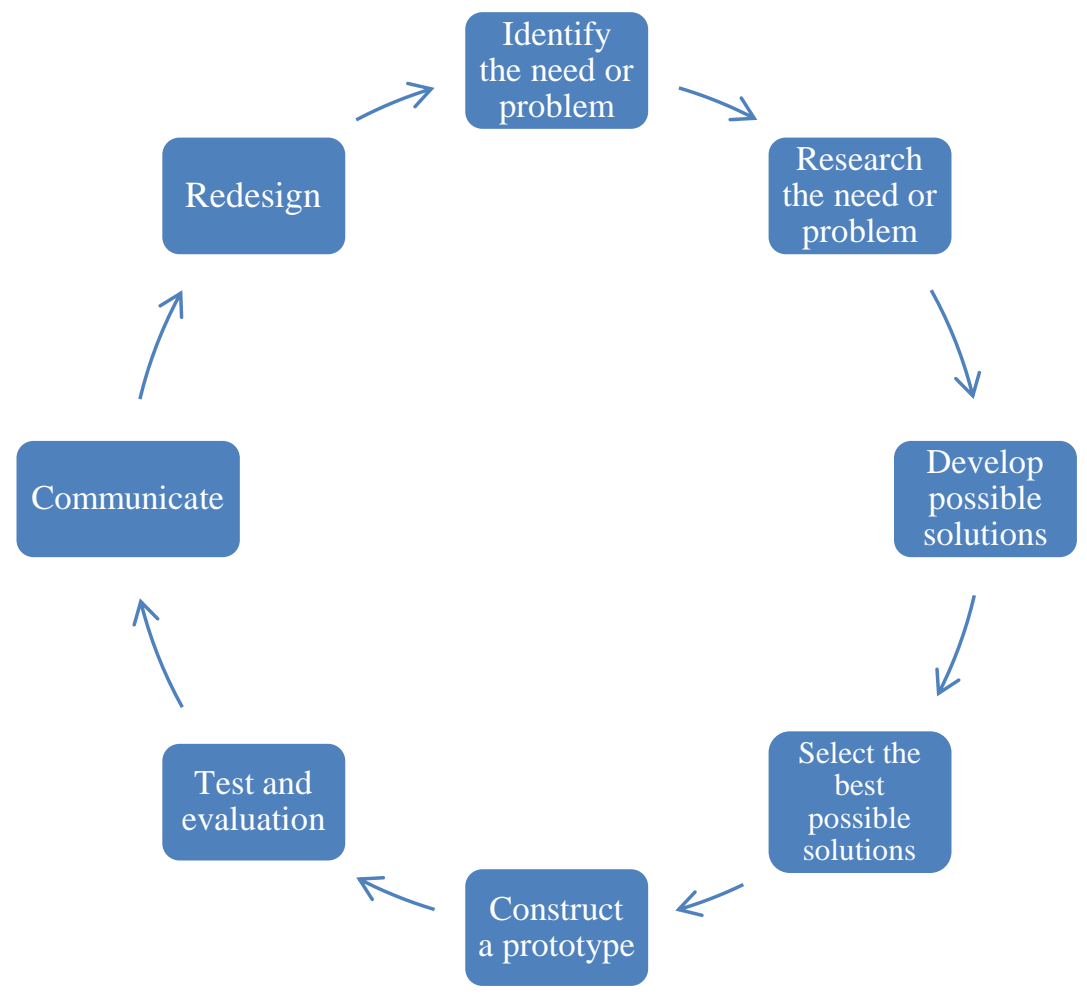

Figure 1. The engineering design process ${ }^{5}$

The current curricular emphasis in the Lamar University civil engineering department is on engineering analysis (Freshman-Junior years) with the course objectives being primarily centered around knowledge acquisition. Upon entering their senior year, students are often found lacking the practical knowledge needed to solve open-ended design problems and generally lack knowledge of the structural building codes. Without proper introduction to the structural building codes and discussion of engineering design processes, expecting fully compliant designs seems like an unreasonable proposition. There is a need to integrate civil engineering design problems at the junior level to better familiarize the students with design codes and accepted design practices.

There is sufficient evidence to suggest project based learning (PBL) is an effective teaching pedagogy that positively changes students' perception of the complex engineering design process $^{6}$ and increases student confidence ${ }^{7}$. Moreover, project based spiral curriculums that integrate design and revisit basic concepts in different contextual arenas, have also been shown to be successful ${ }^{8,9}$ by increasing student motivation, overall satisfaction with the curriculum, and design performance ${ }^{10}$. Integrating a pre-capstone junior-level project can further enhance a design centric curriculum and create a stronger link between the more common freshman cornerstone, sophomore keystone, and senior capstone projects. The students get most of the discipline specific analytical training during their junior year which allows an instructor the 
flexibility to integrate more discipline specific topics and include relevant building codes into a given project. Instructors can integrate the design lectures within a relevant course and present the appropriate building codes and needed analytical work to solve the problem. The project assignment itself can include field work, information synthesis, teamwork, the use of analytical tools, testing, design, and a presentation which are some of the critical elements of the design process ${ }^{4}$. The objective of such a project would be to increase students' awareness of the relevant building codes, the research required for proper compliance, to improve their engineering design self-efficacy, their communication skills, their analytical skills, and to help guide their design strategies and structure their thought processes.

This evidence-based paper summarizes a pre-capstone junior level design project that was administered to students in a civil engineering materials course to increase general engineering design confidence and improve their overall preparedness to successfully complete the senior design project.

\section{Implementation}

The civil engineering materials course at our university is two credit hours and covers topics on basic material response, steel, aggregates, Portland cement, supplementary cementitious materials, concrete, asphalt, timber, and the building codes. There are seven laboratory classes that supplement the topics. The instructor covered all of the material including the labs by week 10 of the semester. On week 11 and 12, the instructor lectured on the different building codes which included IBC, ASCE 7-10, AWC NDS, and ASTM D3737. The instructor conducted two lectures on the gravitational dead and live load, live load reduction, and lateral wind pressures using the directional method and three lectures covering the ASTM D 3737 and NDS 2015 LRFD design procedures for glulam timber beams. The project statement was given to the students on week 11 and due on week 15. The students were allowed to work in teams of 4-5.

During weeks 13-15, the classroom was inverted and the students were required to lecture on specific components of the project which included: wind load calculations, structural analysis and governing load combinations for maximum bending moment, field survey of timber knots, timber strength knot modification factors per ASTM D3737, NDS 2015 glulam design procedures, and glulam optimization with Excel®. During the lectures and designated lab time (once per week for two hours) the students were also given time to work on the structural analysis using STAADPro and the load combinations from ASCE 7-10. After completing the structural analysis, the students began working on the timber knot field survey to determine the $50^{\text {th }}$ and $95^{\text {th }}$ percentile knot size distribution and strength modification factors per ASTM D3737 with the wood provided in the laboratory. The students then determined the optimum beam cross-section based on material cost and moment capacity using both ASTM D3737 and NDS 2015. After completing the optimized design, the students manufactured a quarter-scale glulam 
beam using various timber species (Helm Fir Stud, Douglas Fir Stud, Southern Pine No. 2, and Southern Pine No. 1) polyurethane adhesive, and a mechanical press located in the lab. The students tested the quarter-scale glulam beam using a four-point loading bending test until failure and recorded the maximum load and bending moment. The results were then compared to the design solutions (for a quarter-scale beam) per ASTM D3737 and NDS 2015 to assess the reliability of the calculated design strengths. On the last day of class, during week 15, the students orally presented their final design recommendations.

\section{Methods}

\section{Survey instrument}

The students that completed the project and course were given a 36 item online survey to complete voluntarily. Incomplete surveys were discarded from the analysis. The survey is shown in Table 1. The survey was created by Carberry et al. ${ }^{11}$ and used to measure students' engineering design (ED) and design process (EDP) confidence, motivation, expectancy, and anxiety, respectively, using a 11 point likert scale ranging from 0 to 100 with 10 point increments. The ED measure is quantified by evaluating item 1 and the EDP measure is quantified by pooling items 2-9. Each self-concept dimension (confidence, motivation, expectancy, and anxiety) was inserted into the statement above the items and repeated four times (for each dimension).

After completing the senior capstone project, the same students were given another voluntary survey containing 20 items shown in Table 2 (using a 5 point likert scale ranging from 1 to 5 using one point increments). The first seven items assessed the impact of the pre-capstone project on students' engineering design ability, communication, and technical skills; these questions are denoted with the abbreviation PI and a lower-case letter associated with the criteria 3 ABET learning outcome ${ }^{12}$.

The remaining 13 items measured the senior students' perception of their own preparedness and confidence to conduct engineering design upon completion of their junior year (pre-design courses). The items focused on the students' perception of 1) the importance of learning about building codes and design philosophies (IMPRT), 2) the university's curricular emphasis on lifelong learning (EMPh), broad education (EMPi), and contemporary civil engineering issues (EMPj), 3) student preparation for completing code compliant designs (PREP), and 4) student confidence to conduct engineering design (CNF). Note, the lower-case letters associated the item categories represent the respective criteria 3 ABET learning outcomes. 


\section{Table 1. Post course/project survey}

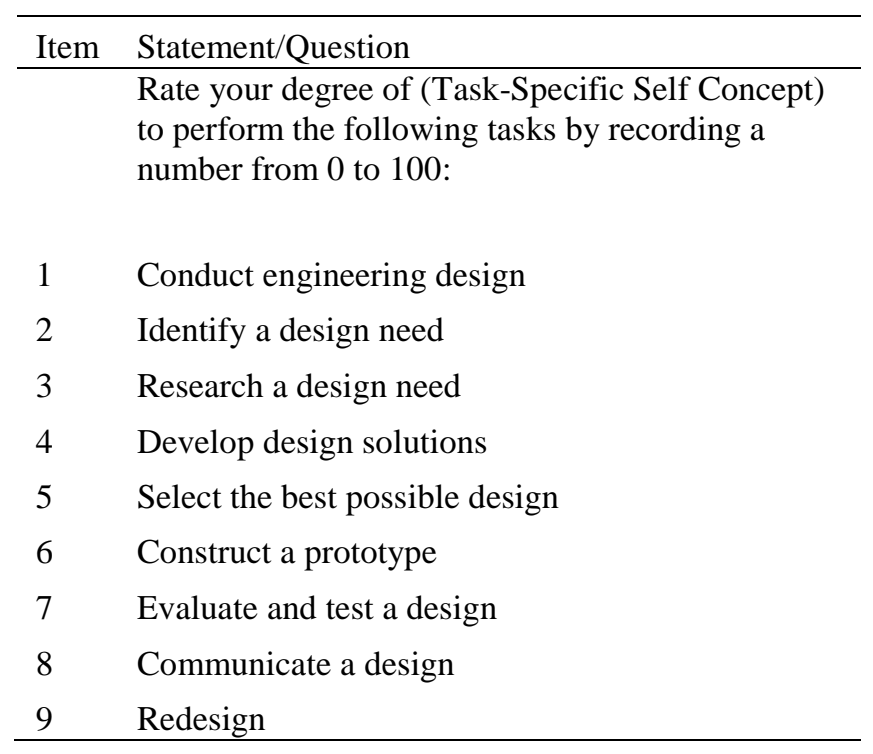

The survey items shown in Table 2 were also given to recent graduates (2014 and 2015) without the inclusion of the PA items since this group did not complete the pre-capstone project.

\section{Hypotheses}

- Upon completion of the pre-capstone project, students will not have significantly high engineering design (ED) and engineering design process (EDP) self-efficacy.

- The students given the pre-capstone project will not have significantly different mean ranks in engineering design confidence and preparedness to conduct engineering design than students not given the project.

\section{Data Analysis}

Students' ED and EDP measures were averaged and compared to the rankings defined by Carberry et al. ${ }^{11}$ (high, moderate, and low levels of confidence, motivation, expectancy, and anxiety). A confidence interval was derived by bootstrapping the data since normality was rejected. The PI (Project Impact) items in the survey shown in Table 2, were also averaged and bootstrapped. 


\section{Table 2. Survey administered to a) senior students upon completion of the capstone project, and $b$ ) recent graduates}

\begin{tabular}{cl}
\hline Item & Statement/Question \\
\hline & Rate how the project affected your ability to (1-No Impact; 3-Moderate Impact 5-High Impact): \\
PIa & Apply knowledge of mathematics, science, and engineering \\
PIc & $\begin{array}{l}\text { Design a system, component, or process to meet desired needs within realistic constraints such } \\
\text { as economic, environmental, social, political, ethical, health and safety, manufacturability, and }\end{array}$ \\
& sustainability \\
PId & Function on multi-disciplinary teams \\
PIe & An ability to identify, formulate, and solve engineering problems \\
PIg & Communicate effectively \\
PIk & Use the techniques, skills, and modern engineering tools necessary for engineering practice \\
PIcode & Develop engineering and code acceptable design solutions in senior-level capstone project
\end{tabular}

After completing your pre-design courses (Freshman-Junior years), how confident were you in your ability to (1-No Confidence; 5-Very Confident):

$\mathrm{CNFa}$ Apply knowledge of mathematics, science, and engineering

$\mathrm{CNFc}$ Design a system, component, or process to meet desired needs within realistic constraints such as economic, environmental, social, political, ethical, health and safety, manufacturability, and sustainability

CNFd Function on multi-disciplinary teams

$\mathrm{CNFe}$ Identify, formulate, and solve engineering problems

CNFf Understand professional and ethical responsibility

$\mathrm{CNFg}$ Communicate effectively

CNFk Use the techniques, skills, and modern engineering tools necessary for engineering practice

To what degree did your pre-design courses (Freshman-Junior years) emphasize or cover the following? (1-None; 3-Somewhat; 5-Significantly):

EMPh The broad education necessary to understand the impact of engineering solutions in a global, economic, environmental, and societal context

EMPi A recognition of the need for, and an ability to engage in life-long learning

EMPj A knowledge of contemporary civil engineering issues

COVcode Building codes and design philosophies

Please answer the questions using the following scale: 1-No; 3-Somehwat; 5-Yes

PREP Upon completing your pre-design courses, do you think you were adequately prepared to develop code acceptable design solutions in your capstone design course?

Please answer the questions using the following scale: 1-Not Important; 3-Somehwat Important; 5 -Very Important

IMPRT How important do you think it would be to learn, in general, about different building codes and design philosophies before your capstone design course? 
The mean rank differences between the student group given the pre-capstone project (test population) and graduates not given the pre-capstone project (control population) were evaluated for significance using the non-parametric rank-sums Mann-Whitney U test. Note, while a significant change cannot be directly attributed to the project itself, the survey provides a reasonable estimate of how students perceive their skills within a given error.

\section{Student survey response population and demographics}

The population demographics for the test (senior students) and control group (recent graduates) are shown in Tables 3 and 4. In both populations, the predominant race is Caucasian. Most students in the test population are between 18 and 24 years old $(78 \%)$ and in the control population, the 18 to 24 and 25 to 34 groups are more evenly distributed. The control population is a few years older in age than the test population. The distribution of GPA is similar; where most have between 3.1 and 3.5. A total of 19 and 13 students fully completed the survey immediately upon completion of the junior-level course and senior capstone project, respectively. A total 17 graduates responded to the survey.

Table 3. Population demographics: gender, race, age

\begin{tabular}{cccccccccc}
\hline Course & \multicolumn{2}{c}{ Gender } & \multicolumn{4}{c}{ Race } & \multicolumn{3}{c}{ Age } \\
\hline & Male & Female & $\begin{array}{c}\text { Asian/Pacific } \\
\text { Islander }\end{array}$ & $\begin{array}{c}\text { African } \\
\text { American }\end{array}$ & Hispanic & White & $\begin{array}{c}18 \text { to } \\
24\end{array}$ & $\begin{array}{c}25 \text { to } \\
34\end{array}$ & $35+$ \\
$\begin{array}{c}\text { Students } \\
\mathrm{N}=19\end{array}$ & $68.4 \%$ & $31.6 \%$ & $0.0 \%$ & $10.5 \%$ & $10.5 \%$ & $78.9 \%$ & $78.9 \%$ & $5.3 \%$ & $15.8 \%$ \\
$\begin{array}{c}\text { Graduates } \\
\mathrm{N}=17\end{array}$ & $64.7 \%$ & $35.3 \%$ & $5.9 \%$ & $0.0 \%$ & $35.3 \%$ & $58.8 \%$ & $41.2 \%$ & $58.8 \%$ & $0.0 \%$ \\
\hline
\end{tabular}

Table 4. Population demographics: work experience and GPA

\begin{tabular}{cccccccc}
\hline Course & \multicolumn{3}{c}{ Work Experience } & \multicolumn{1}{c}{ GPA } \\
\hline & $<1$ year & $1+$ & $5+$ & $2.1-$ & $2.6-$ & $3.1-$ & $3.6-$ \\
& year & year & 2.5 & 3.0 & 3.5 & 4.0 \\
Students & $92.3 \%$ & $0.0 \%$ & $7.7 \%$ & $15.8 \%$ & $31.6 \%$ & $41.2 \%$ & $17.6 \%$ \\
$\mathrm{~N}=19$ & & & & & & & \\
Graduates & $35.3 \%$ & $58.8 \%$ & $5.9 \%$ & $0.0 \%$ & $17.6 \%$ & $47.1 \%$ & $35.3 \%$ \\
$\mathrm{~N}=17$ & & & & & & & \\
\hline
\end{tabular}




\section{Results}

The survey data was analyzed and the results indicate the pre-capstone project significantly impacts students' perception of their ability to conduct civil engineering design. The survey data collected immediately after the completion of the pre-capstone project that was used to analyze ED and EDP, is shown in Table 5 with the corresponding 95\% confidence intervals. According to the ranking system in Carberry et al. ${ }^{11}$, the students completing the project have statistically significant $(p \leq 0.05)$ high student confidence, motivation, and expectancy and an intermediate level of anxiety in engineering design (ED). The students also have statistically significant high student confidence, motivation, and expectancy and an intermediate level of anxiety in the engineering design process (EDP). Note Table 5 shows the ranking system defined in Carberry et al. ${ }^{11}$ and is shown next to the current ED and EDP results.

Table 5. ED and EDP student survey results after the completion of the project/course

\begin{tabular}{ccccccc}
\hline Self- & $\mathrm{ED}(95 \% \mathrm{CI})$, & $\mathrm{N}=19, \mathrm{EDP}(95 \% \mathrm{CI})$ & \multicolumn{2}{c}{ ED Ranks } & \multicolumn{2}{c}{ EDP Ranks } \\
Concept & $\mathrm{N}=19 / 23$ & $\mathrm{~N}=19 / 23$ & High: & Intermediate: & High: & Intermediate: \\
Confidence & $78.42(70.26,86.32)$ & $79.93(76.75,82.98)$ & 80 & 54 & 82 & 61 \\
& & & High: & Intermediate: & High: & Intermediate: \\
Motivation & $85.26(76.84,92.63)$ & $84.90(81.79,87.581)$ & 82 & 63 & 79 & 66 \\
& & & High: & Intermediate: & High: & Intermediate: \\
Expectancy & $77.37(67.89,85.79)$ & $80.00(76.62,83.18)$ & 79 & 54 & 80 & 60 \\
& & & High: & Intermediate: & High: & Intermediate: \\
Anxiety & $56.32(41.57,70.52)$ & $55.76(50.26,61.13)$ & 39 & 49 & 31 & 44 \\
\hline
\end{tabular}

The students were surveyed again after the completion of the senior capstone design course to assess the perceived impact of the pre-capstone project on technical and design abilities (PI), student confidence (CNF), preparedness (PREP), curricular emphasis (EMP), and pre-capstone design importance (IMPRT). The same survey, excluding the PI questions, was also given to recent graduates and the results were compared and summarized in Table 6.

The senior students indicated the pre-capstone project impacted $(3.5+/ 5$ rating at $p \leq 0.05)$ their ability to apply math and science (PIa), their ability to formulate and identify engineering problems (PIe), and ability to communicate effectively (PIg) at $p \leq 0.05$. The senior students also indicated that a greater curricular emphasis was placed on contemporary civil engineering issues (EMPj), and building code and design philosophies (COVcode) at $p \leq 0.05$. Both populations indicate that it is important to introduce design topics and projects before senior year (IMPRT). The student and graduate samples were found to be of adequate size to draw statistically significant conclusions shown in Tables 5-6 (with a type II error power of 0.8, confidence of $95 \%$, and a worst-case Mann-Whitney/t-test asymptotic relative efficiency of 0.864). The students were also shown to have greater confidence in conducting engineering design and using tools to solve modern engineering problems at a lower confidence (90\%). A larger sample size must be used and more data must be collected to increase the confidence level. 
It should be emphasized that the graduates surveyed were asked to retroactively assess their perceived skill and level of preparation before completing their capstone project (at the start of their senior year). They are not assessing their current perceived skill nor preparation to successfully complete professional designs that would be expected when working as a licensed engineer. This is a clear distinction that must be mentioned since their perceived skill and preparation will most like evolve with time and experience. The context of their assessment is constrained to their senior year which may limit some of changes to their perceived skills and abilities which has occurred post-graduation. This context was made very clear on the graduate survey.

\section{Table 6. Post-capstone survey results: recent graduates v. senior students}

\begin{tabular}{cccc}
\hline Item & Graduates N=17 & Students N=13/15 & Difference \\
\hline PIa & - & $4.46^{\mathrm{a}}$ & - \\
PIc & - & 4.15 & - \\
PId & - & 4.38 & - \\
PIe & - & $4.31^{\mathrm{a}}$ & - \\
PIf & - & $4.46^{\mathrm{a}}$ & - \\
PIg & - & $4.46^{\mathrm{a}}$ & - \\
PIk & - & 4.31 & - \\
PAcode & - & $4.38^{\mathrm{a}}$ & - \\
CNFa & 4.00 & 4.00 & 0.00 \\
CNFc & 3.00 & 3.85 & 0.85 \\
CNFd & 4.00 & 4.15 & 0.15 \\
CNFe & 3.76 & 3.92 & 0.16 \\
CNFf & 4.18 & 4.46 & 0.29 \\
CNFg & 4.12 & 4.23 & 0.11 \\
CNFk & 3.18 & 3.85 & 0.67 \\
EMPh & 2.88 & 3.92 & 1.04 \\
EMPi & 3.65 & 4.46 & 0.81 \\
EMPj & 2.76 & 4.08 & $1.31^{*}$ \\
COVcode & 2.47 & 4.08 & $1.61^{*}$ \\
PREP & 2.71 & 3.69 & 0.99 \\
IMPRT & 4.53 & 4.69 & 0.16 \\
\hline
\end{tabular}

*statistically significant, $\mathrm{p} \leq 0.05$

${ }^{a}$ Significantly larger than $3.5, \mathrm{p} \leq 0.05$

\section{Student Comments}

Upon completion of the glulam design project, the students were asked to select their three favorite and their three least favorite project components from a list provided to them on the survey. The values in Table 7 correspond to the number of favorite and least favorite student 
responses that correspond to each of the listed project components. Students were permitted to select both a favorite and least favorite response for the same project component. The total number of responses should be equal to three times the number of respondents if all selected three favorable and three unfavorable responses. The total number of respondents was $\mathrm{N}=13$ and the total number of favorable and unfavorable responses was $\mathrm{N}=37$ and $\mathrm{N}=35$, respectively. The top-ranked favorable project component was load analysis using ASCE 7-10, and the top-ranked unfavorable component was the structural analysis using STAADPro®.

\section{Table 7. Student feedback: Favorable v. Unfavorable}

\begin{tabular}{cccc}
\hline Project Component & $\begin{array}{c}\text { Favorable } \\
\text { Responses }\end{array}$ & Project Component & $\begin{array}{c}\text { Unfavorable } \\
\text { Responses }\end{array}$ \\
\hline ASCE 7-10 & 9 & Structural Analysis & 8 \\
Structural Analysis & 6 & AWC NDS & 5 \\
Teamwork & 5 & ASTM D3737 & 4 \\
Optimization & 4 & Knot Survey & 4 \\
Knot Survey & 4 & ASCE 7-10 & 3 \\
ASTM D3737 & 3 & Optimization & 3 \\
Glulam Manufacturing & 2 & Oral Presentation & 3 \\
Engineering Design & 2 & Teamwork & 3 \\
AWC NDS & 1 & Glulam Manufacturing & 1 \\
Oral Presentation & 1 & Engineering Design & 1 \\
\hline
\end{tabular}

\section{Conclusion}

A pre-capstone project containing several engineering design components: identifying a need or problem, research, development of possible solutions, selecting the best solution, prototype construction, testing, and communication, was given to junior-level students. The students completing the project showed high confidence, motivation, and expectancy in engineering design and the engineering design process, and indicated more curriculum emphasis was placed on engineering design and building codes compared to recent graduates that were not given the project. The students also showed greater confidence in designing a system and using the tools and skills to solve modern engineering problems at a statistical confidence of $90 \%$. Both populations of students and graduates did agree however, that it is important to integrate different design philosophies, building codes, and design projects into the curriculum before senior year. Although the results from this study are promising, more work needs to be done in quantifying the impact on senior-level design performance using an external panel of experts, and more participants need to be surveyed to further increase the level of the confidence of the conclusions drawn here. 


\section{Future Research}

Design performance data collected via a survey from a panel of experts will be collected in the spring 2016 semester. Pre/post surveys (before beginning the project and shortly after completion) will also be given to a new group of junior-level students to both increase response population and further isolate the effects of the pre-capstone project on design performance.

\section{Bibliography}

1. Sheppard, S.D., Macatangay, K., Colby, A. and Sullivan, W.M., 2008.Educating engineers: Designing for the future of the field (Vol. 2). Jossey-Bass.

2. Seely, B.E., 2005. Patterns in the history of engineering education reform: A brief essay. Educating the engineer of 2020: Adapting engineering education to the new century, pp.114-130.

3. Boelskifte, B., 2011. On Designing a Design Engineering Education. InProceedings of the 1st International Workshop on Design in Civil and Environmental Engineering (pp. 63-68). Mary Kathryn Thompson.

4. Einstein, H.H., 2013, September. Design education in civil and environmental engineering. In Proceedings of the 2nd International Workshop on Design in Civil and Environmental Engineering (pp. 112-120). Mary Kathryn Thompson.

5. Massachusetts, D.O.E., 2006. Massachusetts science and technology/engineering curriculum framework.

6. Shekar, A., 2012. RESEARCH-BASED ENQUIRY IN PRODUCT DEVELOPMENT EDUCATION: LESSONS FROM SUPERVISING UNDERGRADUATE FINAL YEAR PROJECTS. International Journal of Industrial Engineering, 19(1).

7. Savage, R.N., Chen, K.C. and Vanasupa, L., 2007. Integrating project-based learning throughout the undergraduate engineering curriculum. Journal of STEM Education: Innovations and Research, 8(3/4), p.15.

8. Selvi, E., Soto-Caban, S., Taylor, R.S. and Wilson, W.R., 2011. Similar Consecutive Bridge Design Projects for Freshmen and Sophomore Level Engineering Courses. In American Society for Engineering Education. American Society for Engineering Education. Vancouver, B.C., Canada, June 26-29

9. Clayton, G., 2010. Introducing engineering design using impromptu design projects. In American Society for Engineering Education. American Society for Engineering Education. Louisville, KY.

10. DiBiasio, D., Clark, W.M., Dixon, A.G., Comparini, L. and O'Connor, K., 1999, November. Evaluation of a spiral curriculum for engineering. In Frontiers in Education Conference, 1999. FIE'99. 29th Annual (Vol. 2, pp. 12D1-15). IEEE.

11. Carberry, A.R., Lee, H.S. and Ohland, M.W., 2010. Measuring engineering design self-efficacy. Journal of Engineering Education, 99(1), p.71.

12. Engineering Accreditation Commission, 1999. Criteria for accrediting engineering programs. Accreditation Board for Engineering and Technology Inc. 


\section{Appendix}

\section{Project Statement}

You are a structural engineer and tasked with designing the main wind frame resisting system (MWFRS) of a church building located in an urban area. The church will have a capacity of 300 people. You are to design the MWFRS with glue laminated wood that satisfies the manufacturing requirements given in AITC 190.1 using the design procedure provided in ASTM D3737 and NDS 2015. You may use either LRFD or ASD.

The MWFRS will be an interior system which will allow the moisture content in the wood to remain below $16 \%$ and will be treated prior to assembly. You are to treat the frame system as beam element with respect to the NDS design specifications. Figure 2 shows a three dimensional drawing of the structure. The frame is fixed to the floor on both ends. As shown in Figure 2, the frame to frame spacing is $5 \mathrm{ft}$. center to center and $2 \times 6$ 's are connected to the MWFRS every 12 in. on the ceiling. The ceiling will be constructed with $1 / 2$ in. drywall, $1 / 2$ in polystyrene insulation, $3 / 8$ in. plywood, and asphalt shingles.

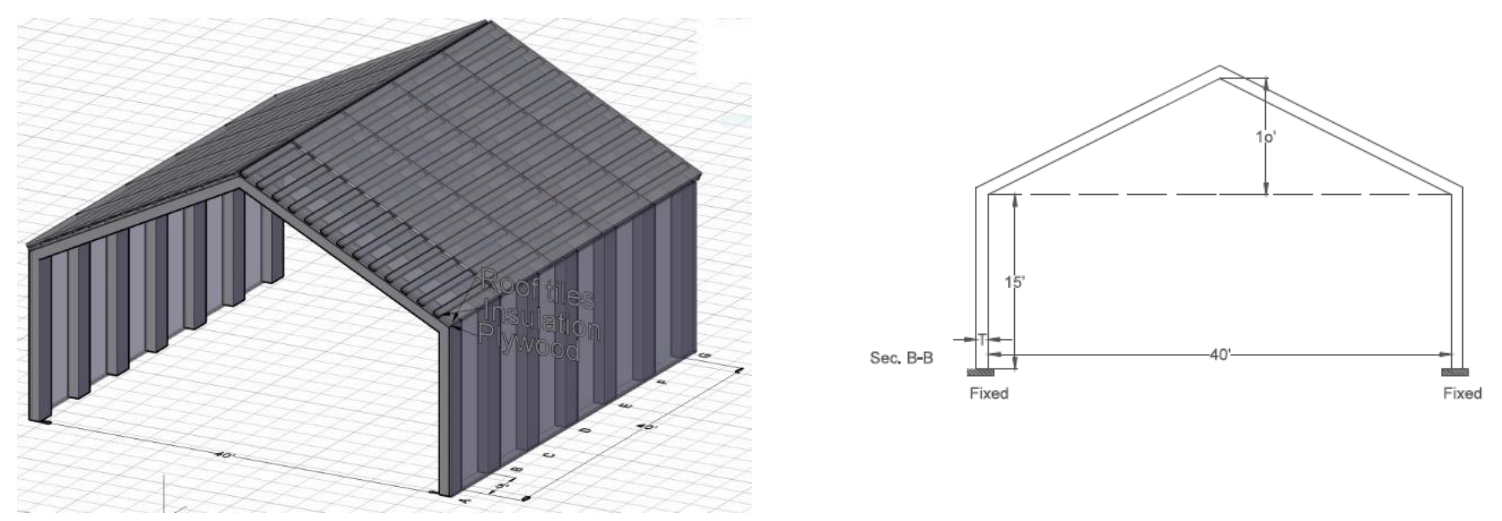

Figure 2: Building geometry

Materials and Supplies:

Each group will have four types of lumber to choose from when designing the glulam beam:

1. No 1 Southern Pine: \$2.06 per board-ft.

2. No 2 Southern Pine: \$ 1.19 per board-ft.

3. Stud Douglas Fir: $\$ 0.75$ per board-ft.

4. Stud Hem Fir: $\$ 0.63$ per board-ft.

*Note, a board-ft. is a unit of measurement used in the timber industry and is defined as follows:

1 board $-f t .=144 \mathrm{in}^{3}$ 
The glue used to build the glulam beam will be a Loctite ${ }^{\circledR}$ industrial grade $8 \mathrm{X}$ premium polyurethane adhesive.

The lumber is color marked in the laboratory as follows:

- No.1 Pine: Red

- No. 2 Pine: Pink

- Douglas Fir: Black

- Hem Fir: Blue

\section{Glulam Manufacturing}

1. Prior to designing the glulam cross-section, each group will be required to conduct a visual survey of the lumber (for each of the four timber grades). The groups are to determine the $50^{\text {th }}$ and $99.5^{\text {th }}$ percentile knot sizes as a percent of the laminate width. The knot sizes are to be recorded every foot. All knot sizes (as a percent of the laminate width) should be tabulated and organized accordingly to determine the 50th and 99.5 percentile values. Assume the knot size population to follow a normal distribution. Groups must survey each piece of wood available in the lab.

2. Each group is to manufacture a "small-scale" version of the glulam in the lab. The width of the beam should be 3.5 in. (You will use 1 x 4 and 2 x 4 laminates). The "small-scale" beam should not have a depth greater than $4.5 \mathrm{in}$. The "small-scale" laminate configuration should be similar to the actual laminate configuration used to construct the structural frame. Actual replicas are not required since there is a limited number of timber and sizes. However, groups are encouraged to design a "small-scale" cross-section that best represents their "large-scale" version.

Each group will have a limited number of timber to construct the "small-scale" beam as follows:

- No. 1 Southern Pine: 2 boards

- No. 2 Southern Pine: 4 boards

- Stud Douglas Fir: 2 boards

- Stud Hem Fir: 2 boards

3. The laminates must be glued horizontally with the industrial grade polyurethane adhesive. The thickness of the adhesive bead should be approximately $1 / 4$ in and placed $1 \mathrm{in}$. from the edge of the laminate as shown in Figure 3. Immediately after gluing the laminates, the beam must be pressed at a pressure between 100 and 200 psi using a 5 ton hydraulic jack for 24 hours as shown in Figure 4. Ask the lab manager for assistance when pressing the glulam beam. 


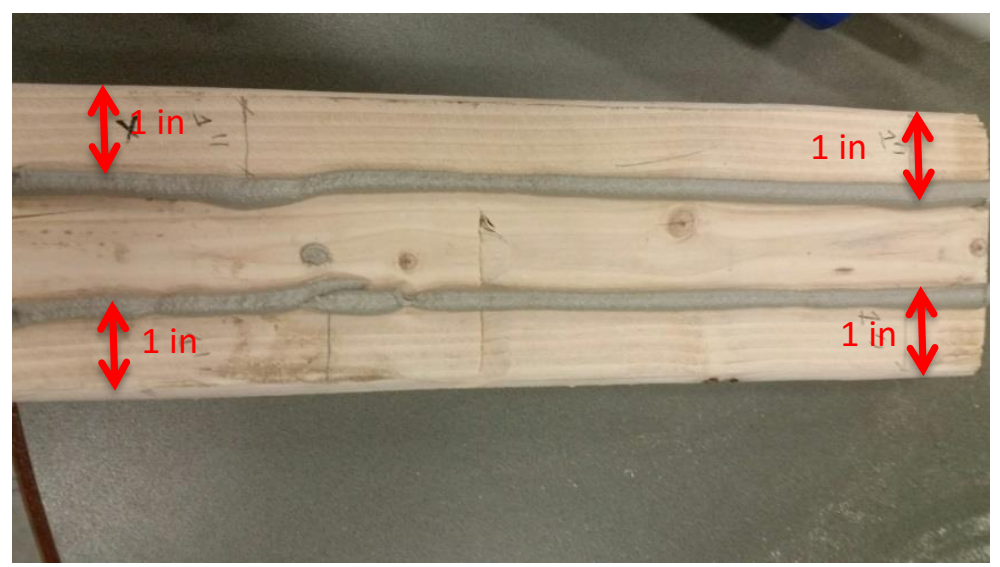

Figure 3: Polyurethane adhesive streaks on timber surface

Glulam Testing:

1. After curing, the beam must be tested under a four-point loading configuration. The loading rate should be designed so the beam fails 5 minutes after the test begins and should be calculated prior to testing. The effective span of the beam (center to center distance between the roller supports) should be 22 in. The inner roller supports should be spaced four inches center to center and positioned two inches on either side of the mid-span location, respectively.

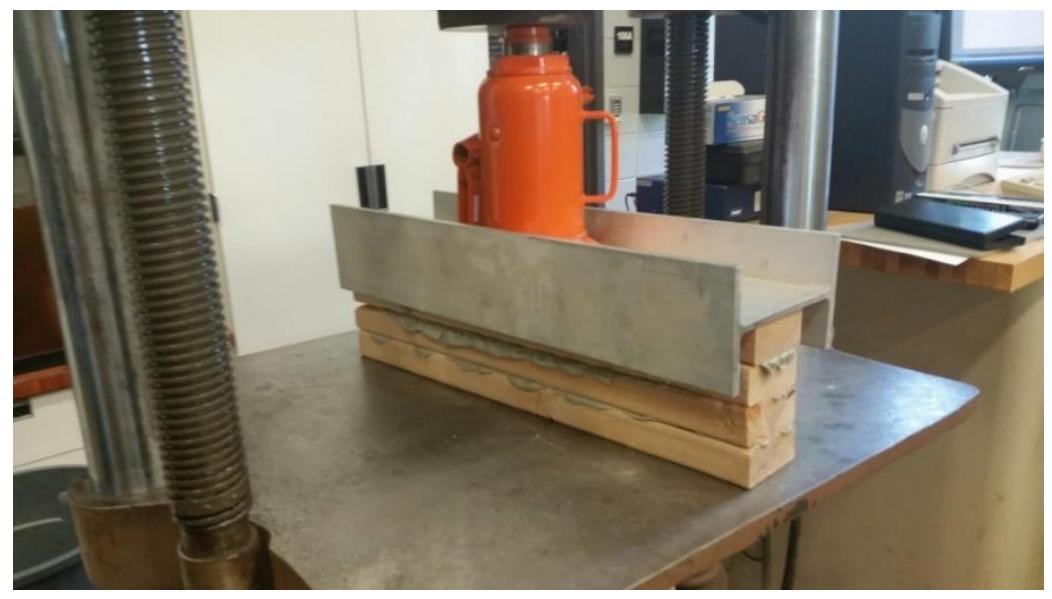

Figure 4: Glue laminated timber press

\section{Deliverables:}

1. Determine the wind loads, roof live loads, and dead loads and all pertinent load combinations therein. 
a. Conduct a structural analysis of the 2-D MWFRS system to determine the critical moment and critical load combination using only Case Ia wind loading and the directional method.

2. Conduct a visual survey of the lumber knot sizes and determine the $50 \%$ and $99.5 \%$ percentile knot size per board foot (as per ASTM D3737).

3. Design an optimal glulam cross-section that will have the capacity to withstand the moment generated by the wind, dead, and live roof load whilst minimizing material cost.

4. Manufacture a "small-scale" glulam beam using the materials provided in the lab and test under four-point loading. The beam length should be 24 in. and the effective span should be 22 in.

- Calculate the maximum bending moment for the "small-scale" beam and compare this value to the experimental result.

5. Build a power point presentation detailing the analysis, all calculations, design assumptions, manufacturing procedures, test data, and final design recommendations.

Schedule:

- Timber knot survey: Date

- StaadPro structural analysis: Date

- Glulam design and optimization: Date

- Glulam Manufacturing and Pressing: Date

- Groups 1 and 2: Date

- Groups 3 and 4: Date

- Four Point Testing: Date

Due Date:

- Power Point Presentations:

- The presentations sholud be emailed to the instructor by the shown time. The groups will then be asked to present their findings and recommendations on the date shown. 
Sample student presentation
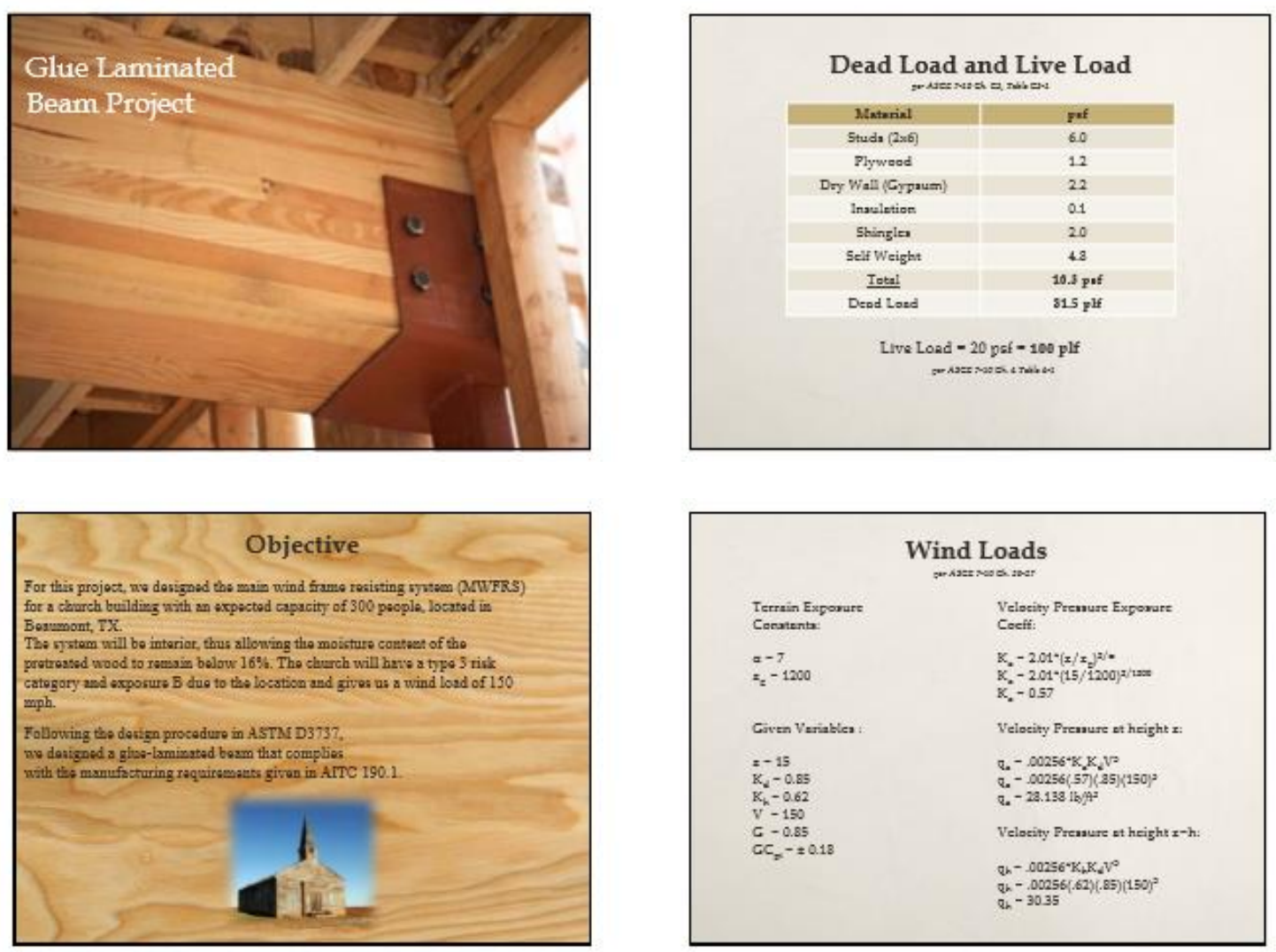

As illuatrated in the figurea below, the frams-to-frame pyocing is 5 feet. The strueture is 40 feet wide end the freme is fixed to the floor on both endi.

The eciling will eonaint of the following boilding materiais 4" Drywall

14" Polyrtyreme Lnaulation

Anphit Shinglex
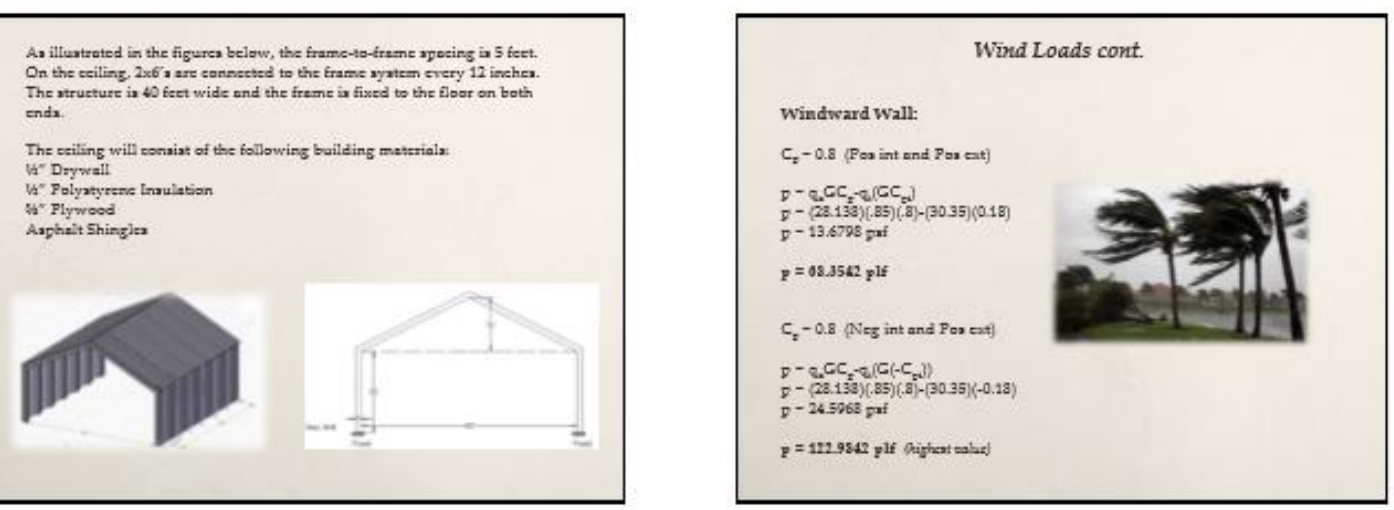

Figure 5. Sample student design solution 

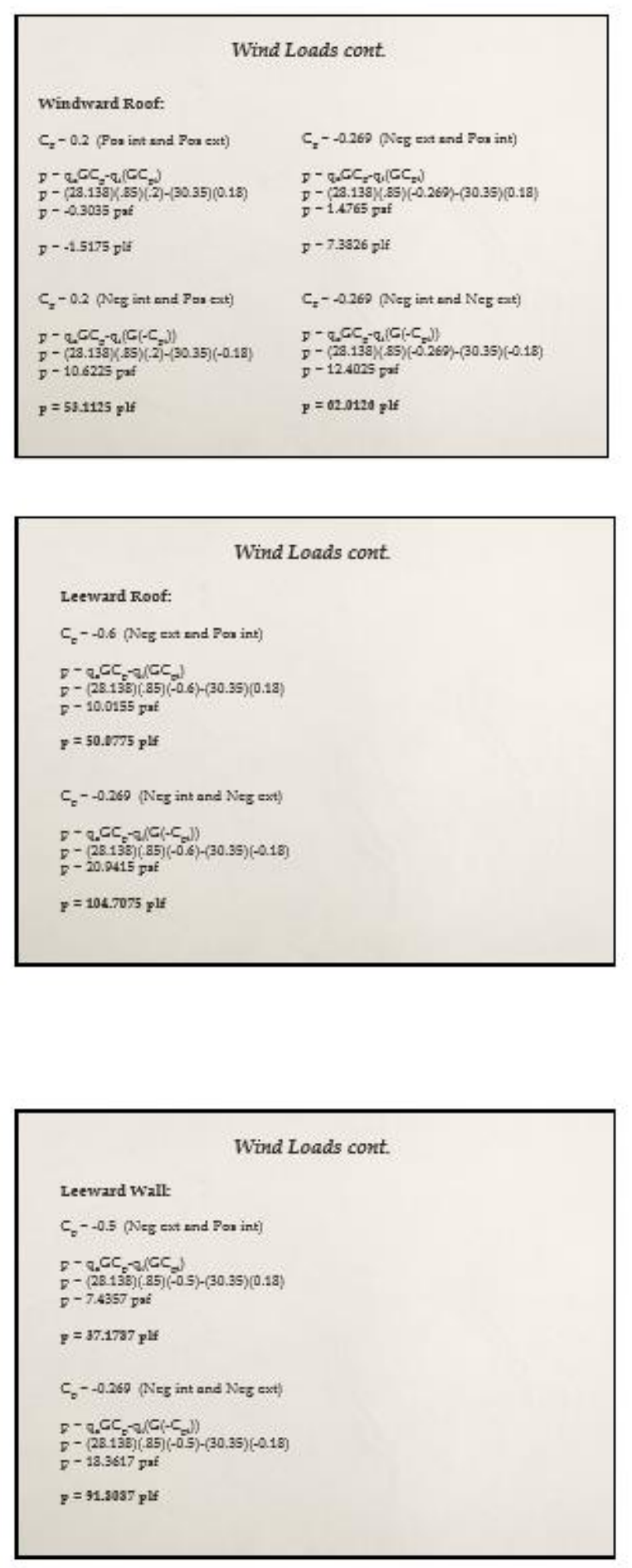
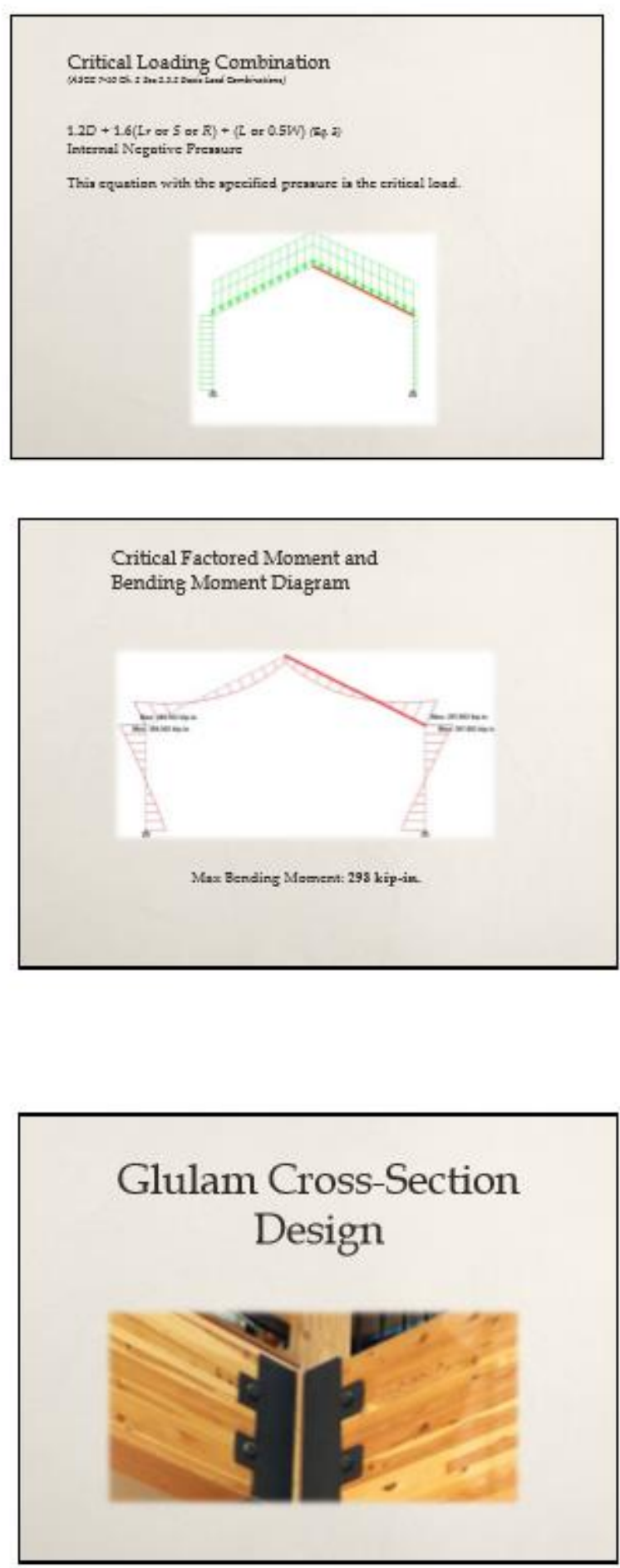

Figure 5. Sample student design solution (continued) 

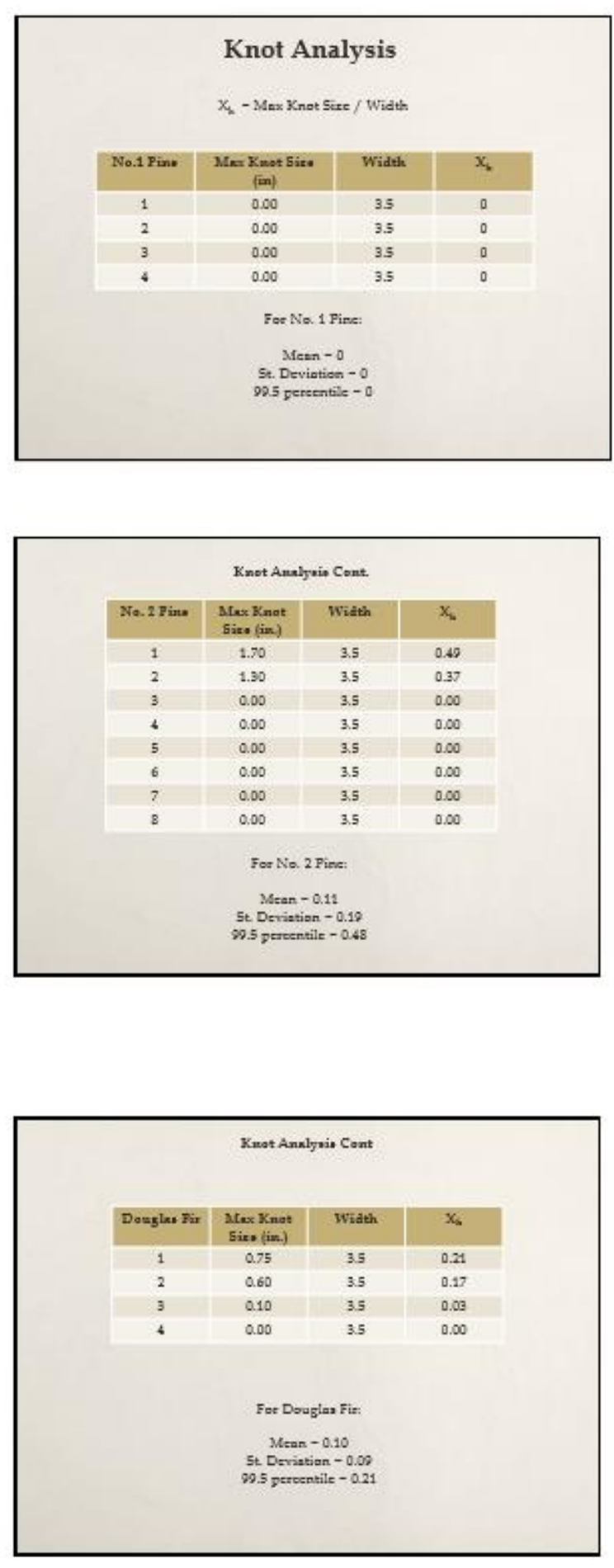

Figure 5. Sample student design solution (continued)

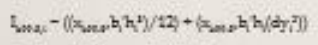

Moments of Inertia, $I_{w}$ I for Optimal Cross Section:

Cretere

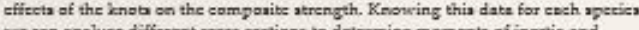
we ean enelyse different erou vections to determins momenta of incrtiv and

especity.

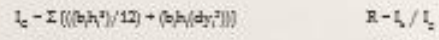

$\mathrm{I}_{\mathrm{C}}=1152$ in $^{4} \quad \mathrm{~F}_{\mathrm{H}}=0.198$

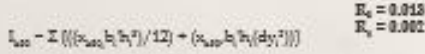

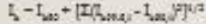

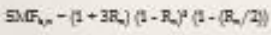

$I_{4 s}=157.1$ int $^{\circ}$

$\mathrm{I}_{\mathrm{s}=0}=03.1 \mathrm{in}$

$\mathrm{I}_{\mathrm{wa}}=20.9 \mathrm{im}$

$\mathrm{I}_{\mathrm{bat}}=2.7 \mathrm{in}^{2}$

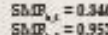

$\sin =0.999$

$\sin 2 x=0.939$
$\operatorname{sag} x=0.999$

\section{Glulam Design}

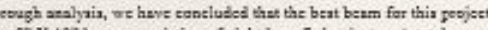
oment, war chouen.

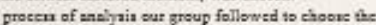

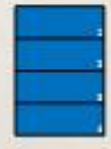

Virual for erom-acetion is the mid ayan to the tog of the beam 


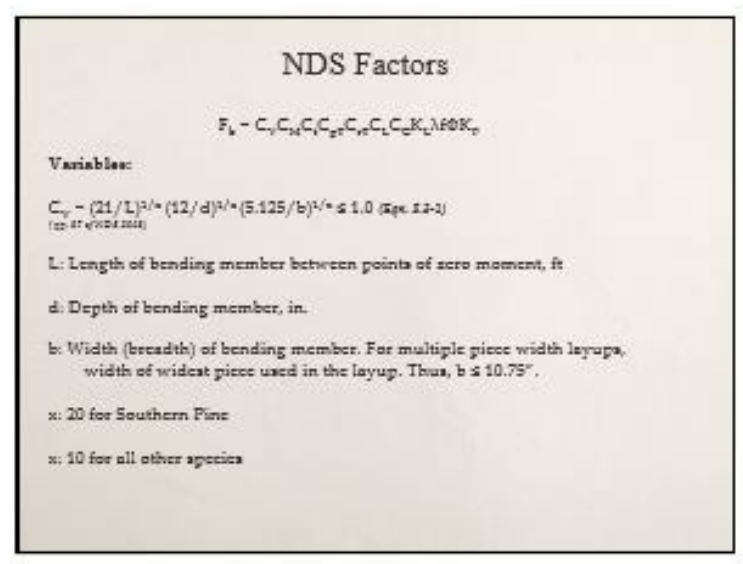

$c_{n}=1$

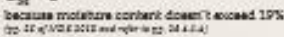

$C_{1}=1$

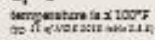

$c_{x=1}$

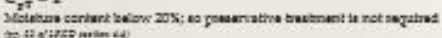

$c_{\mathrm{n}, \mathrm{T}}=1$

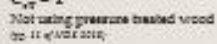

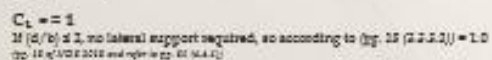

$C_{E}-1-2000(t / R)^{2}=1$

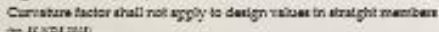

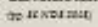

Calculating Bending Stress and Moment Capacity For the Optimal Cross Section Chosen

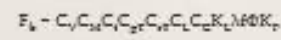

$\mathrm{g}_{6}=354 \mathrm{pai}$

$\left.\mathrm{M}_{6}-\left(\left\langle\mathrm{F}_{\mathrm{\gamma}} / \mathrm{K}_{p}\right) \oplus\right) \mathrm{I}_{\mathrm{T}}\right) /\left(\mathrm{C}_{\gamma} \cdot 1000\right\}$

$\mathrm{MI}_{\mathrm{b}}=310 \mathrm{kip}-\mathrm{in}$
Visual for Cross Sections from Mid Span to Top of Beam

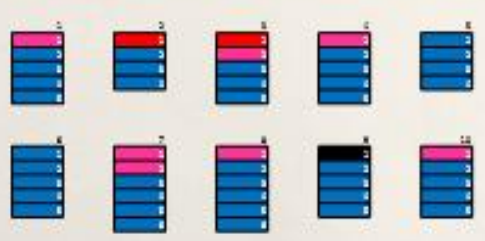

Bled: No. 1 Firse

Fink: No. 2 Fine

Black: Dougles Fir

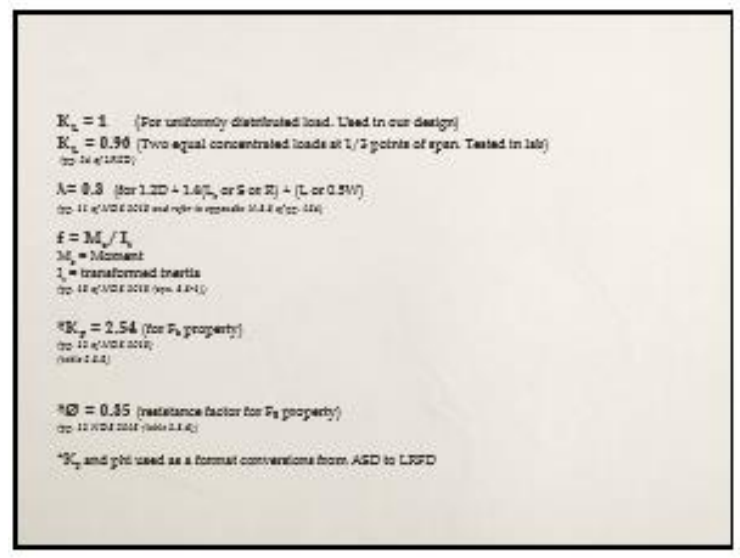

The table below showa the dets obtained from the anelyais of 10 differeat Creas xectiona. The previous atepa were followed for cosh onc.

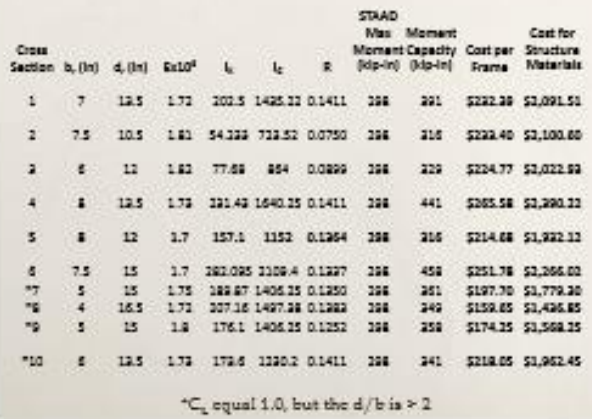

Figure 5. Sample student design solution (continued) 

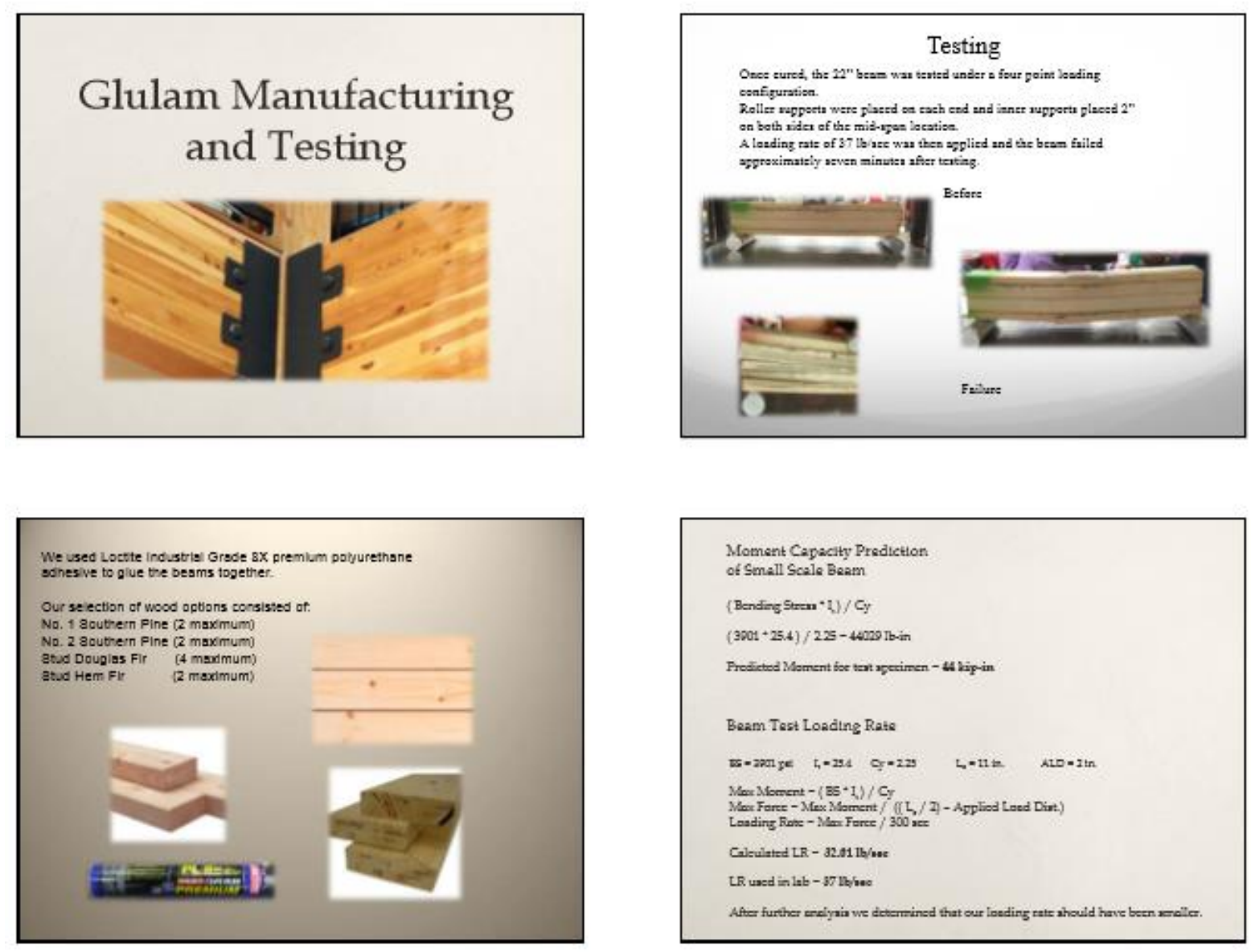

Moment Cayacity Predtetion

of Small Scele Beam

(Bending Stren' 1 ) / $C y$

$(3001+25.4) / 225-40259 \mathrm{Ib}$ in

Frodicted Marnent foe tent xpecimen - A kip-in

Beam Test Loading Rate

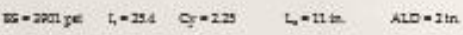

Voex Mberent $-(35+1) / C y$

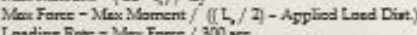

Caleulated LR - 32.011 1b/uec

LR uned in lab - MV Lblow

After further exciyai we determined that our loeding rats ahould have been veoller.

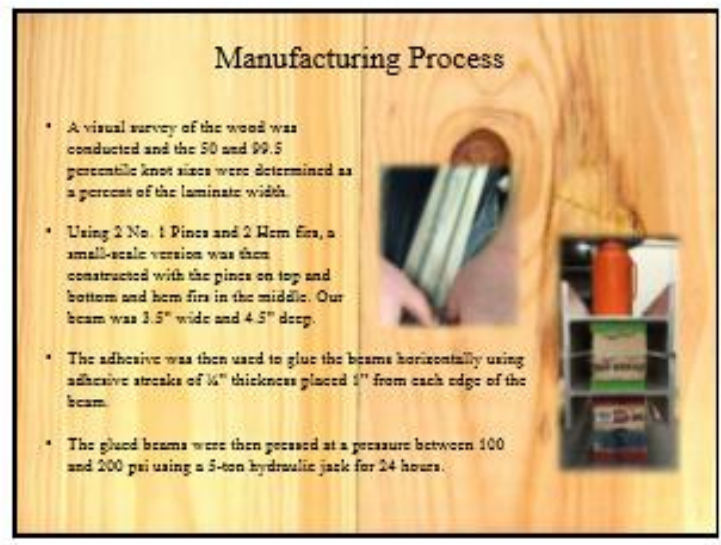

\section{Discussion}

Due to our agetimen being only 2 feet long, our beam experiemeed a xmall umount of ahear freilure, which sffested oar revalt slightly. To securately tent for allowable bending stem, the xyecimen woold heve to be mueh longer

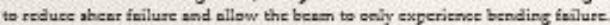
Another sourte of error could be thet our wood was not exactly what it wer. lebeled as. If the mood labeled No. 1 Fine, was octarliy = No. 2 Pins, then the modalua of elextieity would chnenge and affert the calculations.

Tent Reaulta.

Leod $-11852 \mathrm{Iba}$. Mex Mement $-53370 \mathrm{lk}-\mathrm{in}$ Max Mament - 53.4 kip-in Bending Stren -4729 o

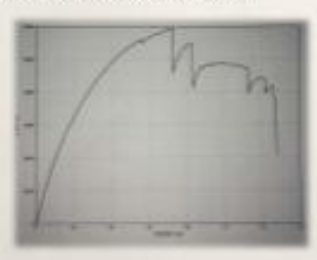

Figure 5. Sample student design solution (continued) 